\title{
Examining the Impact of Turkish Couples' Intimacy Levels in Romantic Relationship on Children's Anxiety During the COVID-19 Pandemic
}

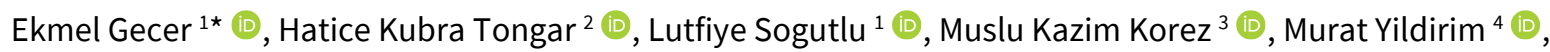 \\ Omer Akgul ${ }^{1}$ (1), Enise Akgul ${ }^{2}$ (D), Kubra Baysal ${ }^{2}$ (1)
}

${ }^{1}$ Psychology Department, University of Health Sciences, Istanbul, TURKEY

${ }^{2}$ Independent Researcher, TURKEY

${ }^{3}$ Medical School, Selcuk University, Konya, TURKEY

${ }^{4}$ Department of Psychology, Faculty of Arts and Sciences, Agri Ibrahim Cecen University, Agri, TURKEY

*Corresponding Author: ekmel.gecer@sbu.edu.tr

Citation: Gecer E, Tongar HK, Sogutlu L, Korez, MK, Yildirim M, Akgul A, Akgul E, Baysal K. Examining the Impact of Turkish Couples' Intimacy Levels in Romantic Relationship on Children's Anxiety During the COVID-19 Pandemic. Electron J Gen Med. 2022;19(3):em370. https://doi.org/10.29333/ejgm/11875

ARTICLE INFO

Received: 22 Jan. 2022

Accepted: 3 Mar. 2022

\begin{abstract}
Intimacy refers to closeness and an expressive and personal romantic relationship between couples/partners. More importantly, intimacy in romantic relationships is known to influence children's well-being and mental health. Couples who suffer from a lack of intimacy in their relationship are more vulnerable to psychophysiological disorders, depression and other non-psychiatric disorders and these disorders may have an impact on the children living with them. Under today's circumstances, little is known about the link of intimacy in romantic relationships with children's anxiety particularly within the context of the COVID-19 pandemic. Therefore, this study examines the relationship between intimacy in romantic and children's anxiety levels during COVID-19 disease.

Participants were 12,126 Turkish couples (mean age=35.27 \pm 5.37 ) who completed the intimacy in romantic relationship scale and state-trait anxiety inventory for children online. Socio-demographic data form was created to measures variables such as age, gender, and the COVID-19 experiences. The results suggest that single couples were found to have a better romantic relationship than married couples. Self-disclosure, physical attraction, support, and trust were found to be related to anxiety levels of children. This pattern of results highlights the importance of intimacy in a romantic relationship on children anxiety levels in the face of adversity which have important implications for research and practice.
\end{abstract}

Keywords: COVID-19 pandemic, romantic relationship, family communication, intimacy, child anxiety

\section{INTRODUCTION}

Intimacy is defined as closeness, similarity, an emotional and personal romantic relationship that require comprehension of the individual [1]. Although the meaning of intimacy may vary according to age, gender, education, and culture, it comprises various dimensions including emotional, psychological, physical, sexual, timewise, communicational, social, intellectual, and spiritual [2]. The level of experienced intimacy in the relationships significantly influence individuals' social development and adoption [3,4], mental and physical health [5]. Furthermore, intimacy contributes to the relationship of couples and helping them to cope with daily pressures and stress $[4,6]$ and increases their harmony and satisfaction with sexual experiences [7-9].

Couples who suffer from a lack of intimacy in their relationship are more vulnerable to psychophysiological disorders, depression, and other non-psychiatric disorders $[6,10,11]$. A study conducted in Austria during the COVID-19 pandemic suggests that the quality of the relationship between couples is significantly related to psychological well-being. A positive relationship between the couples is found to serve as a protective factor of the mental health and psychological health of couples [12]. A lack of satisfaction in an intimate relationship between couples is one of the most important reasons that push people to get psychotherapy [13] and is a ground for divorce $[2,14]$.

Children from an early age witness their parents' romantic relationships [15]. Children with a positive family environment are more capable to develop a model helping them to control and adapt to their emotions. In a study [16], it was shown that $60 \%$ of the participants who were happy with their lives were those who also had parents with a good relationship. On the contrary, children who witness the conflict between their mothers and fathers have poor psychological well-being and more mental health problems [17-19] than those who witness a better romantic relationship [20]. Furthermore, studies demonstrated that parents who experience psychological problems in their relationships have children and adolescents who are more vulnerable to anxiety, depression and other psychological disorders [21]. In light of the literature, therefore, 
Table 1. Demographical characteristics of the participants

\begin{tabular}{|c|c|}
\hline Demographic characteristics & $\begin{array}{c}\text { Participants } \\
(n=12,126)\end{array}$ \\
\hline Age (years), mean \pm SD & $35.27 \pm 5.37$ \\
\hline Female gender, $\mathrm{n}(\%)$ & $12,030(99.2)$ \\
\hline Marital status (married), $\mathrm{n}(\%)$ & $11,962(98.6)$ \\
\hline Smoking, $\mathrm{n}(\%)$ & $2,155(17.8)$ \\
\hline Alcohol, $\mathrm{n}(\%)$ & $84(0.7)$ \\
\hline Use of drug, $n(\%)$ & $125(1)$ \\
\hline Psychiatric disease, $\mathrm{n}(\%)$ & $2,208(18.2)$ \\
\hline Use of psychiatric drug, $n(\%)$ & $2,380(19.6)$ \\
\hline COVID-19 history, $\mathrm{n}(\%)$ & $2,933(24.2)$ \\
\hline Hospitalization due to the COVID-19, n(\%) & $147(1.2)$ \\
\hline $\begin{array}{l}\text { Number of people in an immediate family with COVID- } \\
19 \text { diseases, } n(\%)\end{array}$ & $7,423(61.2)$ \\
\hline $\begin{array}{l}\text { Number of deaths in an immediate family from COVID- } \\
19 \text { diseases, } n(\%)\end{array}$ & $1,187(9.8)$ \\
\hline Vaccination, $\mathrm{n}(\%)$ & $401(3.3)$ \\
\hline \multicolumn{2}{|l|}{ Marital adjustment, $\mathrm{n}(\%)$} \\
\hline Decreased & $1,669(13.8)$ \\
\hline Not changed & $7,805(64.4)$ \\
\hline Increased & $2,652(21.9)$ \\
\hline \multicolumn{2}{|l|}{ Marital satisfaction, $\mathrm{n}(\%)$} \\
\hline Decreased & $2,095(17.3)$ \\
\hline Not changed & $7,427(61.2)$ \\
\hline Increased & $2,604(21.5)$ \\
\hline \multicolumn{2}{|l|}{ Relationship with children, $\mathrm{n}(\%)$} \\
\hline Decreased & $1,674(13.8)$ \\
\hline Not changed & $4,938(40.7)$ \\
\hline Increased & $5,514(45.5)$ \\
\hline
\end{tabular}

Note. SD: Standard deviation

this study aims to examine the influence of the intimacy level of Turkish couples during COVID-19 on children's anxiety levels. The results of this study will shed a light on the process of intervention and prevention programs that would be implemented during and aftermath of the pandemic.

\section{MATERIALS AND METHODS}

\section{Participants}

The sociodemographic and clinical characteristics of the participants are reported in Table 1. A total of 12,126 participants completed the questionnaires. In our sample, $99.2 \%$ of the participants were females, and the mean age of participants was 35.27 years $(S D=5.37)$. The majority of participants were married $(98.6 \%)$ and $24.2 \%$ of them experienced symptoms of COVID-19 disease (outpatient or inpatient).

\section{Measures}

Socio-demographic data form was created to measures variables such as age, gender, and the COVID-19 experiences.

Intimacy in romantic relationship scale (IRRS) [22] includes 4 sub-scales (self-disclosure, physical attraction, support, and trust) with 17 items and each item is rated on a 4-point Likert scale ranging from 1 (never) to 4 (always). Only one item (the $7^{\text {th }}$ one) is reversely graded. A total score can be obtained by recoding negatively worded items with higher scores indicating higher intimacy levels. In this study, the Cronbach alpha coefficient was .88 .

State-trait anxiety inventory for children (STAI-C) [23] was adopted to Turkish [24]. It is one of the most frequently used self-report instruments for evaluating children's anxiety and can be applied to children between 9-12. It consists of two twenty-item scales for state and trait anxiety and all items are rated on a 3-point Likert scale ranging from 1 (almost never) to 4 (always). Children are required to report how they feel their anxiety level at the present moment. A total score can be created by summing all items on the state and trait subscales. The test could be applied individually or in a group. In this study, the Cronbach's alpha coefficient of STAI-C was .82.

\section{Procedure}

An online survey was used to collect data given that it is the most realistic and feasible method during the coronavirus pandemic [25]. Participants were invited to take part in the study via social networking sites. Before filling out the online survey, informed consent was obtained from all participants. All participants were made aware of the confidentiality and anonymity of responses, and their right to withdraw from the study at any time of participation without giving any legitimate reasons.

\section{Ethical Statement}

All procedures performed in studies involving human participants were under the ethical standards of the institutional and/or national research committee and with the 1964 Helsinki declaration and its later amendments or comparable ethical standards.

\section{Statistical Analysis}

All statistical analysis was performed using IBM SPSS 21.0 for Windows. Shapiro-Wilk's normality test, Q-Q plots, skewness and kurtosis values were used to check the normality of the data. Levene's test was used to check the homogeneity of the group's variances. The numerical variables were expressed as meantstandard deviation. The categorical variables were described as counts ( $\mathrm{n}$ ) and percentages (\%). Independent samples t-test, Welch's t-test, Mann-Whitney $U$ test, one-way ANOVA (analysis of variance) followed by Tukey HSD posthoc test, Welch's F test followed by Games-Howell post-hoc test and Kruskal Wallis test followed by Dunn test with Bonferroni correction was run to determine whether there was a statistically significant difference between demographical variables, parents' romantic intimacy and their children's state-trait anxiety level score. Moreover, Pearson and Spearman's rho correlation coefficients were used to examine the relationship between scales. The Cronbach's alpha coefficient was used to evaluate the internal consistency reliability estimates of the scales. A value of $p$ less than .05 was considered statistically significant.

\section{RESULTS}

Descriptive statistics for the participants in the study are given in Table 1 . Of the 12,126 participants, 12,030 were women, and the mean age of the participants was $35.27 \pm 5.37$ years. $98.6 \%$ of the participants were married, $17.8 \%$ were smoking, $0.7 \%$ were using alcohol, and $1 \%$ were using drug. $18.2 \%$ of the participants had a psychiatric illness and $19.6 \%$ of the participants were using psychiatric medication. Regarding the experience with COVID-19, $24.2 \%$ of the participants had a history of COVID-19, and $1.2 \%$ were hospitalized because of the COVID-19 virus. While the rate of people who had COVID-19 in their first-degree relatives was $61.2 \%$, the rate of their first- 
Table 2. The mean, standard deviation, and reliability coefficients of the scales and the items in the scales

\begin{tabular}{|c|c|c|c|c|c|c|c|c|c|c|}
\hline Scales/factors & Mean & SD & Skew & Kurt & $\boldsymbol{\alpha}$ & 1.1. & 1.2. & 1.3. & 1.4. & 2 \\
\hline 1. IRRS & 20.31 & 3.51 & 1.13 & -0.33 & .86 & $.86^{\star \star}$ & $.58^{\star \star}$ & $.41^{\star \star}$ & $.78^{\star \star}$ & $-.07^{\star \star}$ \\
\hline 1.1. Self-disclosure & 6.65 & 1.80 & 0.70 & -0.96 & .81 & 1 & $.38^{\star \star}$ & $.30^{\star \star}$ & $.51^{\star \star}$ & $-.09^{\star \star}$ \\
\hline 1.2. Physical attraction & 4.47 & 0.95 & 2.35 & 5.07 & .75 & & 1 & $.25^{\star \star}$ & $.37^{\star \star}$ & $-.07^{\star \star}$ \\
\hline 1.3. Support & 4.19 & 0.61 & 3.95 & 17.60 & .70 & & & 1 & $.27^{\star \star}$ & $-.02^{\star}$ \\
\hline 1.4. Trust & 5.00 & 1.29 & 1.01 & -0.33 & .75 & & & & 1 & $-.03^{\star}$ \\
\hline 2. STAI-C & 47.45 & 3.86 & -0.64 & 1.42 & .91 & & & & & 1 \\
\hline
\end{tabular}

Note. ${ }^{\star \star}$ Correlation is significant at the 0.01 level; ${ }^{*}$ Correlation is significant at the 0.05 level; IRRS: Intimacy in romantic relationship scale;

STAI-C: State-trait anxiety inventory for children; SD: Standard deviation; Skew: Skewness; Kurt: Kurtosis; a: Cronbach's alpha

degree relatives lost due to this disease was $9.8 \%$. Of the participants, $3.3 \%$ were vaccinated. While marital adjustment decreased by $13.8 \%$ during the COVID-19 pandemic, it was observed that there was no change by $64.4 \%$ and this adjustment increased by $21.9 \%$. Similarly, the rate of those with decreased satisfaction among spouses was $13.8 \%$, while the rate of those who did not experience any change was $61.2 \%$, and the rate of those with an increase in satisfaction was $21.5 \%$. Results also suggest that there was a $45.5 \%$ increase in the level of communication between parents and children during the pandemic process.

The reliability coefficients of the scales and the descriptive statistics regarding the items in the subscales and total scales are given in Table 2 . The reliability coefficient ranged between acceptable-excellent levels. The overall mean score for the IRSS scale was $20.31 \pm 3.51$, and that $47.45 \pm 3.86$ for the STAI-C scale. As the average scores of the items in the scales were assessed, the intimacy in romantic relationship quality in the parents and the state anxiety perception of children and young people were at a low level during the COVID-19 pandemic.

The relationship between the intimacy in a romantic relationship in parents and the state anxiety scales in adolescents during the COVID-19 pandemic with the demographic characteristics of the participants are given in Table 3. According to the results, there was no difference in the perceptions of IRRS and STAI-C against the participants' gender (except IRRS trust subscale), alcohol use, use of drug, COVID-19 history, hospitalization due to the COVID-19, number of people in an immediate family with COVID-19 disease, and vaccination $(p>05)$.

Table 3. The comparison of the scale means according to the demographical characteristics of the participants

\begin{tabular}{|c|c|c|c|c|c|}
\hline & \multicolumn{2}{|c|}{ Category 1} & \multicolumn{2}{|c|}{ Category 2} & \multirow[b]{2}{*}{ p-value } \\
\hline & Mean & SD & Mean & SD & \\
\hline Gender & \multicolumn{2}{|c|}{ Female $(n=12,030)$} & \multicolumn{2}{|c|}{ Male $(n=96)$} & \\
\hline IRRS self-disclosure & 6.65 & 1.80 & 6.45 & 1.73 & $0.277^{1}$ \\
\hline IRRS physical attraction & 4.47 & 0.95 & 4.44 & 1.03 & $0.231^{2}$ \\
\hline IRRS support & 4.19 & 0.61 & 4.25 & 0.74 & $0.534^{2}$ \\
\hline IRRS trust & 5.00 & 1.29 & 4.53 & 0.98 & $<.001^{3}$ \\
\hline IRRS total & 20.31 & 3.51 & 19.67 & 3.55 & $0.072^{1}$ \\
\hline STAI-C & 47.45 & 3.86 & 47.21 & 3.91 & $0.540^{1}$ \\
\hline Marital status & \multicolumn{2}{|c|}{ Married $(n=11,962)$} & \multicolumn{2}{|c|}{ Single $(n=164)$} & \\
\hline IRRS self-disclosure & 6.63 & 1.79 & 7.68 & 2.09 & $<.001^{3}$ \\
\hline IRRS physical attraction & 4.46 & 0.93 & 5.63 & 1.79 & $<.001^{2}$ \\
\hline IRRS support & 4.18 & 0.56 & 5.29 & 1.72 & $<.001^{2}$ \\
\hline IRRS trust & 4.98 & 1.28 & 5.98 & 1.53 & $<.001^{3}$ \\
\hline IRRS total & 20.25 & 3.42 & 24.58 & 6.27 & $<.001^{3}$ \\
\hline STAI-C & 47.45 & 3.86 & 47.42 & 4.09 & $.925^{1}$ \\
\hline Smoking & \multicolumn{2}{|c|}{ No $(n=9,971)$} & \multicolumn{2}{|c|}{ Yes $(n=2,155)$} & \\
\hline IRRS self-disclosure & 6.61 & 1.78 & 6.83 & 1.86 & $<.001^{3}$ \\
\hline IRRS physical attraction & 4.45 & 0.92 & 4.59 & 1.07 & $<.001^{2}$ \\
\hline IRRS support & 4.19 & 0.59 & 4.21 & 0.66 & $.700^{2}$ \\
\hline IRRS trust & 4.95 & 1.27 & 5.20 & 1.37 & $<.001^{3}$ \\
\hline IRRS total & 20.20 & 3.44 & 20.83 & 3.75 & $<.001^{3}$ \\
\hline STAI-C & 47.47 & 3.84 & 47.35 & 3.97 & $.184^{1}$ \\
\hline Alcohol & \multicolumn{2}{|c|}{ No $(n=12,042)$} & \multicolumn{2}{|c|}{ Yes $(n=84)$} & \\
\hline IRRS self-disclosure & 6.65 & 1.80 & 6.73 & 1.83 & $.684^{1}$ \\
\hline IRRS physical attraction & 4.47 & 0.95 & 4.75 & 1.31 & $.190^{2}$ \\
\hline IRRS support & 4.19 & 0.61 & 4.26 & 0.76 & $.418^{2}$ \\
\hline IRRS trust & 4.99 & 1.29 & 5.24 & 1.44 & $.124^{3}$ \\
\hline IRRS total & 20.30 & 3.50 & 20.98 & 4.17 & $.145^{3}$ \\
\hline STAI-C & 47.45 & 3.86 & 46.89 & 4.49 & $.185^{1}$ \\
\hline Use of drug & \multicolumn{2}{|c|}{ No $(n=12,001)$} & \multicolumn{2}{|c|}{ Yes $(n=125)$} & \\
\hline IRRS self-disclosure & 6.64 & 1.80 & 6.93 & 1.95 & $.079^{1}$ \\
\hline IRRS physical attraction & 4.47 & 0.95 & 4.64 & 1.12 & $.059^{2}$ \\
\hline IRRS support & 4.19 & 0.61 & 4.18 & 0.66 & $.352^{2}$ \\
\hline IRRS trust & 4.99 & 1.29 & 5.13 & 1.41 & $.292^{3}$ \\
\hline IRRS total & 20.30 & 3.51 & 20.88 & 3.70 & $.067^{1}$ \\
\hline STAI-C & 47.46 & 3.86 & 46.70 & 4.21 & $.067^{3}$ \\
\hline
\end{tabular}


Table 3 (Continued). The comparison of the scale means according to the demographical characteristics of the participants

\begin{tabular}{|c|c|c|c|c|c|}
\hline & \multicolumn{2}{|c|}{ Category 1} & \multicolumn{2}{|c|}{ Category 2} & \multirow[b]{2}{*}{ p-value } \\
\hline & Mean & SD & Mean & SD & \\
\hline Psychiatric disease & \multicolumn{2}{|c|}{ No $(n=9,918)$} & \multicolumn{2}{|c|}{ Yes $(n=2,208)$} & \\
\hline IRRS self-disclosure & 6.60 & 1.78 & 6.88 & 1.85 & $<.001^{3}$ \\
\hline IRRS physical attraction & 4.44 & 0.91 & 4.63 & 1.10 & $<.001^{2}$ \\
\hline IRRS support & 4.18 & 0.57 & 4.27 & 0.74 & $<.001^{2}$ \\
\hline IRRS trust & 4.94 & 1.26 & 5.24 & 1.38 & $<.001^{3}$ \\
\hline IRRS total & 20.15 & 3.42 & 21.01 & 3.79 & $<.001^{3}$ \\
\hline STAI-C & 47.44 & 3.82 & 47.50 & 4.03 & $.501^{3}$ \\
\hline Use of psychiatric drug & \multicolumn{2}{|c|}{ No $(n=9,746)$} & \multicolumn{2}{|c|}{ Yes $(n=2,380)$} & \\
\hline IRRS self-disclosure & 6.59 & 1.78 & 6.88 & 1.85 & $<.001^{3}$ \\
\hline IRRS physical attraction & 4.44 & 0.92 & 4.60 & 1.07 & $<.001^{2}$ \\
\hline IRRS support & 4.18 & 0.58 & 4.24 & 0.69 & $<.001^{2}$ \\
\hline IRRS trust & 4.94 & 1.27 & 5.22 & 1.37 & $<.001^{3}$ \\
\hline IRRS total & 20.16 & 3.44 & 20.93 & 3.71 & $<.001^{3}$ \\
\hline STAI-C & 47.43 & 3.79 & 47.52 & 4.13 & $.345^{3}$ \\
\hline COVID-19 history & \multicolumn{2}{|c|}{ No $(n=9,193)$} & \multicolumn{2}{|c|}{ Yes $(n=2,933)$} & \\
\hline $\begin{array}{c}\text { IRRS self-disclosure } \\
\end{array}$ & 6.67 & 1.81 & 6.57 & 1.76 & $.005^{3}$ \\
\hline IRRS physical attraction & 4.47 & 0.95 & 4.47 & 0.95 & $.952^{2}$ \\
\hline IRRS support & 4.20 & 0.61 & 4.19 & 0.60 & $.902^{2}$ \\
\hline IRRS trust & 5.01 & 1.31 & 4.94 & 1.24 & $.007^{3}$ \\
\hline IRRS total & 20.35 & 3.53 & 20.17 & 3.44 & $.014^{3}$ \\
\hline STAI-C & 47.39 & 3.83 & 47.63 & 3.94 & $.004^{1}$ \\
\hline Hospitalization due to the COVID-19 & \multicolumn{2}{|c|}{ No $(n=11,979)$} & \multicolumn{2}{|c|}{ Yes $(n=147)$} & \\
\hline IRRS self-disclosure & 6.65 & 1.80 & 6.63 & 1.71 & $.888^{1}$ \\
\hline IRRS physical attraction & 44.7 & 0.95 & 4.67 & 1.16 & $.026^{2}$ \\
\hline IRRS support & 4.20 & 0.61 & 4.16 & 0.47 & $.963^{2}$ \\
\hline IRRS trust & 4.99 & 1.29 & 5.04 & 1.28 & $.668^{1}$ \\
\hline IRRS total & 20.31 & 3.51 & 20.50 & 3.52 & $.498^{1}$ \\
\hline STAI-C & 47.45 & 3.86 & 47.29 & 4.05 & $.606^{1}$ \\
\hline Number of people in immediate family with COVID-19 disease & \multicolumn{2}{|c|}{ No $(n=4,703)$} & \multicolumn{2}{|c|}{ Yes $(n=7,423)$} & \\
\hline IRRS self-disclosure & 6.64 & 1.80 & 6.65 & 1.80 & $.582^{1}$ \\
\hline IRRS physical attraction & 4.47 & 0.95 & 4.47 & 0.95 & $.531^{2}$ \\
\hline IRRS support & 4.18 & 0.58 & 4.21 & 0.62 & $.002^{2}$ \\
\hline IRRS trust & 4.98 & 1.29 & 5.00 & 1.29 & $.389^{1}$ \\
\hline IRRS total & 20.27 & 3.48 & 20.34 & 3.53 & $.282^{1}$ \\
\hline STAI-C & 47.52 & 3.77 & 47.40 & 3.92 & $.109^{3}$ \\
\hline Number of deaths in immediate family from COVID-19 disease & \multicolumn{2}{|c|}{ No $(n=10,939)$} & \multicolumn{2}{|c|}{ Yes $(n=1,187)$} & \\
\hline IRRS self-disclosure & 6.64 & 1.80 & 6.69 & 1.81 & $.430^{1}$ \\
\hline IRRS physical attraction & 4.47 & 0.95 & 4.49 & 0.96 & $.506^{2}$ \\
\hline IRRS support & 4.19 & 0.60 & 4.21 & 0.63 & $.317^{2}$ \\
\hline IRRS trust & 4.99 & 1.29 & 5.03 & 1.31 & $.316^{1}$ \\
\hline IRRS total & 20.30 & 3.50 & 20.41 & 3.57 & $.277^{1}$ \\
\hline STAI-C & 47.48 & 3.84 & 47.19 & 4.05 & $.056^{3}$ \\
\hline Vaccination & \multicolumn{2}{|c|}{ No $(n=11,725)$} & \multicolumn{2}{|c|}{ Yes $(n=401)$} & \\
\hline IRRS self-disclosure & 6.64 & 1.80 & 6.72 & 1.87 & $.386^{1}$ \\
\hline IRRS physical attraction & 4.47 & 0.95 & 4.49 & 1.02 & $.521^{2}$ \\
\hline IRRS support & 4.20 & 0.61 & 4.15 & 0.53 & $.193^{2}$ \\
\hline IRRS trust & 4.99 & 1.29 & 5.02 & 1.32 & $.729^{1}$ \\
\hline IRRS total & 20.31 & 3.50 & 20.39 & 3.65 & $.650^{1}$ \\
\hline STAI-C & 47.44 & 3.86 & 47.57 & 3.82 & $.536^{1}$ \\
\hline
\end{tabular}

Note. IRRS: Intimacy in romantic relationship scale; STAI-C: State-trait anxiety inventory for children. ${ }^{1}$ Independent sample t-test; ${ }^{2}$ Mann-Whitney U test; ${ }^{3}$ Welch's t-test

On the other hand, IRRS scores were significantly higher in single individuals than in married, in smokers compared to non-smokers, in those with the psychiatric disease compared to those without psychiatric disease, and in those who use psychiatric medication compared to those who did not use psychiatric medication $(p<.05)$.

Table 4 shows the changes in marital adjustment, marital satisfaction, and relationship with children during COVID-19 pandemic.

As seen from Table 4, those with increased marital adjustment during the COVID-19 process had significantly higher IRRS and STAI-C scores than those whose marital adjustment did not change and decreased. Similarly, those with increased marital satisfaction had significantly higher IRRS and STAI-C scores than those whose marital adjustment did not change and decreased while those whose marital satisfaction did not change had higher IRRS and STAI-C scores than those who decreased.

On the other hand, while the IRRS scores of those whose relationship with children did not change and those who increased were higher than those who decreased. No significant relationship was found between the relationship with children in the STAI-C score. 
Table 4. Changes in marital adjustment, marital satisfaction, and relationship with children during COVID-19 pandemic

\begin{tabular}{|c|c|c|c|c|}
\hline & Decreased & Not changed & Increased & p-value \\
\hline Marital adjustment & $n=1,669$ & $n=7,805$ & $n=2,652$ & \\
\hline IRRS self-disclosure & $7.73 \pm 1.88^{\mathrm{a}}$ & $6.57 \pm 1.77^{\mathrm{b}}$ & $6.18 \pm 1.55^{c}$ & $<.001^{1}$ \\
\hline IRRS physical attraction & $4.96 \pm 1.29^{a}$ & $4.45 \pm 0.92^{b}$ & $4.23 \pm 0.62^{c}$ & $<.001^{2}$ \\
\hline IRRS support & $4.43 \pm 0.89^{a}$ & $4.18 \pm 0.58^{b}$ & $4.10 \pm 0.41^{c}$ & $<.001^{2}$ \\
\hline IRRS trust & $6.84 \pm 1.45^{\mathrm{a}}$ & $4.91 \pm 1.24^{b}$ & $4.71 \pm 1.11^{\mathrm{c}}$ & $<.001^{1}$ \\
\hline IRRS total & $22.95 \pm 3.94^{\mathrm{a}}$ & $20.12 \pm 3.37^{b}$ & $19.21 \pm 2.71^{\mathrm{c}}$ & $<.001^{1}$ \\
\hline STAI-C & $47.70 \pm 3.97^{\mathrm{a}}$ & $47.55 \pm 3.80^{\mathrm{a}}$ & $47.00 \pm 3.95^{b}$ & $<.001^{1}$ \\
\hline Marital satisfaction & $n=2,095$ & $n=7,427$ & $n=2,604$ & \\
\hline IRRS self-disclosure & $7.65 \pm 1.87^{\mathrm{a}}$ & $6.54 \pm 1.76^{\mathrm{b}}$ & $6.15 \pm 1.53^{c}$ & $<.001^{1}$ \\
\hline IRRS physical attraction & $4.92 \pm 1.25^{\mathrm{a}}$ & $4.44 \pm 0.91^{b}$ & $4.21 \pm 0.60^{c}$ & $<.001^{2}$ \\
\hline IRRS support & $4.40 \pm 0.85^{a}$ & $4.17 \pm 0.57^{b}$ & $4.09 \pm 0.40^{c}$ & $<.001^{2}$ \\
\hline IRRS trust & $5.72 \pm 1.45^{\mathrm{a}}$ & $4.90 \pm 1.24^{b}$ & $4.69 \pm 1.09^{c}$ & $<.001^{1}$ \\
\hline IRRS total & $22.68 \pm 3.86^{\mathrm{a}}$ & $20.05 \pm 3.36^{\mathrm{b}}$ & $19.14 \pm 2.64^{c}$ & $<.001^{1}$ \\
\hline STAI-C & $47.69 \pm 3.97^{\mathrm{a}}$ & $47.52 \pm 3.81^{\mathrm{a}}$ & $47.05 \pm 3.90^{b}$ & $<.001^{1}$ \\
\hline Relationship with children & $n=1,674$ & $n=4,938$ & $n=5,514$ & \\
\hline IRRS self-disclosure & $7.18 \pm 1.89^{a}$ & $6.58 \pm 1.79^{b}$ & $6.54 \pm 1.75^{b}$ & $<.001^{1}$ \\
\hline IRRS physical attraction & $4.69 \pm 1.11^{\mathrm{a}}$ & $4.47 \pm 0.95^{b}$ & $4.41 \pm 0.89^{c}$ & $<.001^{2}$ \\
\hline IRRS support & $4.31 \pm 0.76^{\mathrm{a}}$ & $4.19 \pm 0.60^{b}$ & $4.16 \pm 0.55^{c}$ & $<.001^{2}$ \\
\hline IRRS trust & $5.36 \pm 1.39$ & $4.97 \pm 1.30$ & $4.91 \pm 1.24$ & $<.001^{1}$ \\
\hline IRRS total & $21.54 \pm 3.78$ & $20.21 \pm 3.50$ & $20.02 \pm 3.35$ & $<.001^{1}$ \\
\hline STAI-C & $47.70 \pm 3.97^{\mathrm{a}}$ & $47.48 \pm 3.82$ & $47.34 \pm 3.86^{b}$ & $.003^{3}$ \\
\hline
\end{tabular}

Note. Data were presented as mean \pm standard deviation; IRRS: Intimacy in romantic relationship scale; STAI-C: State-trait anxiety inventory for children; ${ }^{1}$ Welch's F test followed by Games-Howell test; ${ }^{2}$ Kruskal Wallis test followed by Dunn test with Bonferroni correction; ${ }^{3}$ One-way ANOVA test followed by Tukey HSD test

\section{DISCUSSION AND CONCLUSION}

This study aimed to examine the relationship between Turkish parents' intimacy levels and their children's anxiety intensities. One of the most important results of this study suggests that the intimacy level in parents correlates with the children's anxiety. While the children, whose parents' intimacy levels are high, do not tend to be anxious; those whose parent's intimacy levels are low, are more likely to be anxious. The existing literature also seems to support these findings. If parents have increasing psychological disorders and stress, especially under extraordinary conditions such as pandemics, fires, and earthquakes, children and adolescents living with them become more defenceless to anxiety, depression, psychosomatic feelings, and other psychological disorders $[12,16,21]$. Accordingly, constructive relationships between couples positively impact their children and make them have stronger mental health which helps them find solutions throughout difficult times and overcome the problems they may face [16].

Besides, our study also found a significant difference in intimacy/romantic relationship levels of married and unmarried parents. Single couples were found to have a better romantic relationship than married ones. The results of some previous studies also conform with this finding. Domestic and/or partner conflict during COVID-19 caused by increasing job loss, duty of care, illnesses negatively impacted romantic relationships and caused large numbers of divorces [26-28]. State of being male or female had a significant difference only in "trust" sub-scale of romantic intimacy scales. This result also corresponds to [29] in which they suggest that gender does not have a meaningful impact on the quality of the relationship between partners

Furthermore, the state of romantic relationship and intimacy between the couples during COVID-19 considerably influence their marital adjustment and satisfaction. The participants who affirmed that their marital adjustment decreased also complained about their worsening romantic intimacy. Yet those who found no change or pointed an increase in their marital adjustment indicated that their romantic intimacy levels also become better. In this regard, our study demonstrates that marital adjustment and happiness substantially influence the anxiety level of the children. Children of the couples whose marital adjustment and happiness decreased have more unusual levels of anxiety while those whose parents' marital adjustments did not change or/but increased had a more moderate degree of STAI-C. These outcomes also confirm previous research. Romantic intimacy and marital adjustment and happiness are important factors that impact the psychological wellness of the couples and the quality of their relationship $[6,7,12]$. Therefore, children in families with a lack of romantic relationships are more likely to have a higher level of anxiety [21,26]. Previous studies also showed that worsening marital adjustment cause behavioural disorders [24]. Similarly, it was found that low marital adjustment and problems in associations negatively affect children's psychological and physical development [25].

The romantic intimacy between the partners influences their communication with the children as well. While the communication of the couples, whose romantic relationship is low, with their children is not good enough; those who stated that their romantic intimacy did not change but increased indicated that their relationship with the children also got better which may also be read the other way round. Namely, a romantic relationship positively influences the parents' communication with their children or vice versa. Furthermore, the STAI-C of the children is affected by the change in connection with their mums and dads. The state-anxiety levels of the children whose relations with their parents are good, seem to be lower than those who have insufficient communication with their parents. Therefore, findings that point to the increasing activities within the family or communication among the family members during COVID-19 are of importance in this context [30]. 
There is a significant link between romantic intimacy levels of couples and their probability of having a psychiatric illness or using psychiatric drugs. The inquiry found out that the romantic intimacy levels of those who had a psychiatric disorder are higher than those who did not have psychiatric illnesses. In a similar saying, the romantic intimacy levels of those who used psychiatric drugs are better than those who did not have psychiatric drugs. Moreover, the more anxiety level reduces in children, the less they seem to appeal for emergency cares at hospitals. Remarkably, this study found a notable positive relationship between smoking and romantic intimacy which says that couples who smoke have higher levels of a romantic relationship than those who do not.

The current study has two main strengths. First, the data collection held between 01 March- 01 April 2021 was completed within a month. This comprehensive data collection procedure allowed us to timely assess how the COVID-19 pandemic influenced Turkish couples' romantic intimacy and their relationship with the children. Second, large sample size was recruited via an online survey, and this helped us to reach a wide range of participants from different socioeconomic backgrounds.

Yet the study has several limitations that need to be addressed in future studies. First, as we used an online approach to collect data, those who are unable to use the internet or have limited internet access were not sufficiently represented. Nevertheless, collecting data via an online survey is a practical approach to adopt as a face-to-face interview or inviting people into a lab is not feasible during the COVID-19 outbreak [31]. Second, only a limited number of psychological variables were examined in this study. Future research should consider investigating other psychological factors that can affect the romantic relationship of spouses and their communication with their children. Third, a cross-sectional survey was used to collect data. Therefore, longitudinal design should be used to make a causal inference between the variables. Finally, males (0.8\%) and females (99.2\%) were not proportionally distributed. As such, the results cannot be generalized to males. Future research with approximately equal number of males and females should be conducted to improve the generalizability of findings.

In conclusion, long lockdowns and increasing doubts about COVID-19 affected the families and other members of the society almost in all phases by disrupting routines, changing relationships and roles, altering childcare, schooling, recreational activities, and hospital treatments. Therefore, trying to understand the way couples and their children experience these changes may help to guide future research on the effects of COVID-19 among family members. Moreover, understanding the physical, mental, romantic, and emotional impacts of the COVID-19 pandemic for parents and their children will help NGOs, academics, and policymakers to design their approaches more professionally to support families and children for the duration of the pandemic and later.

Author contributions: All authors have sufficiently contributed to the study, and agreed with the results and conclusions.

Funding: No funding source is reported for this study.

Declaration of interest: No conflict of interest is declared by authors.

\section{REFERENCES}

1. Bagarozzi DA. Enhancing intimacy in marriage: A clinician's guide. London: Routledge; 2001.

2. Kardan-Souraki M, Hamzehgardeshi Z, Asadpour I, Mohammadpour RA, Khani S. A review of marital intimacyenhancing interventions among married individuals. Glob J Health Sci. 2016;8(8):53109. https://doi.org/ 10.5539/gjhs.v8n8p74 PMid:27045400 PMCid:PMC5016345

3. Erikson EH. Childhood and society. New York: W. W. Norton; 1963.

4. Hertemir KM, Blumer MLC. The couple and family technology framework: Intimate relationships in a digital age. London: Routledge; 2013.

5. Moss BF, Schwebel Al. Defining intimacy in romantic relationships. Fam Relat. 1993;42(1):31-7. https://doi.org/ $10.2307 / 584918$

6. Yoo H, Bartle-Haring S, Day RD, Gangamma R. Couple communication, emotional and sexual intimacy, and relationship satisfaction. J Sex Marital Ther. 2014;40(4):275-93. https://doi.org/10.1080/0092623X.2012. 751072 PMid:24111536

7. Harper JM, Schaalje BG, Sandberg JG. Daily hassles, intimacy, and marital quality in later life marriages. Am J Fam Ther. 2000;28(1):1-18. https://doi.org/10.1080/ 019261800261770

8. Hinchliff S, Gott M. Perceptions of well-being in sexual illhealth: What role does age play? J Health Psychol. 2004;9(5):649-60. https://doi.org/10.1177/1359105304045 361 PMid:15310419

9. Impett EA, Finkel EJ, Strachman A, Gable SL. Maintaining sexual desire in intimate relationships: The importance of approach goals. J Pers Soc Psychol. 2008;94(5):808-23. https://doi.org/10.1037/0022-3514.94.5.808 PMid: 18444740

10. Duffey TH, Wooten HR, Lumadue CA, Comstock DC. The effects of dream sharing on marital intimacy and satisfaction. J Couple Relatsh Ther. 2004;3(1):53-68. https://doi.org/10.1300/J398v03n01_04

11. Kim M. The effect of marital intimacy, sex communication, and sexual satisfaction on the marital satisfaction for Korean middle-aged women. J Next Gener Inf Tech. 2013;4(8):441-8.

12. Pieh $C, O^{\prime}$ Rourke T, Budimir S, Probst T. Relationship quality and mental health during COVID-19 lockdown. PLOS One. 2020;15(9): e0238906. https://doi.org/10.1371/ journal.pone.0238906 PMid:32915878 PMCid:PMC7485771

13. Horowitz MJ. States of mind: Analysts of change in psychotherapy. New York: Plenum Publishing; 1979.

14. Gecer E. Pandemics, cultural psychology and politics: A local approach. Cukurova Uni J Soc Sci Inst. 2020;29(3):55067. https://doi.org/10.35379/cusosbil.750289

15. Daks JS, Rogge RD. Examining the correlates of psychological flexibility in romantic relationship and family dynamics: A meta-analysis. J Contextual Behav Sci. 2020;18:214-38. https://doi.org/10.1016/j.jcbs.2020.09.010

16. Ermisch J, lacovou M, Skew A. Family relationships. In: McFall SL, Garrington C, editors, Early findings from the first wave of understanding society, the UK's household longitudinal study. Colchester: Institute for Social and Economic Research, University of Essex; 2001. p. 7-14. 
17. Alshehri NA, Yildirim M, Vostanis P. Social support and mental health problems. Arab J Psychiatr. 2020;31(2):13043.

18. Masoom Ali S, Yildirim M, Abdul Hussain S, Vostanis P. Selfreported mental health problems and post-traumatic growth among children in Pakistan care homes. Asia Pac J Soc Work. 2020;30(1):62-76. https://doi.org/10.1080/02185 385.2019.1710726

19. Yildirim $M$, Iqbal $N$, Khan MM, O'Reilly $M$, Vostanis $P$. Psychosocial needs and supports for street children in India: Stakeholder perspectives: Psychosocial supports for street children. Int J Child Dev Ment Health. 2020;8(2):19 28.

20. Grych JH, Seid M, Fincham FD. Assessing marital conflict from the child's perspective: The children's perception of interparental conflict scale. Child Dev. 1992;63(3):558-72. https://doi.org/10.2307/1131346 PMid:1600822

21. Cobham VE, McDermott B, Haslam D, Sanders MR. The role of parents, parenting and the family environment in children's post-disaster mental health. Curr Psychiatry Rep. 2016;18(6):53. https://doi.org/10.1007/s11920-0160691-4 PMid:27086314

22. Ercan H. Intimacy scale development study in romantic relationships. Int J Soc Stud. 2019;18:207-31.

23. Spielberger CD. Manual for the state-trait anxiety inventory for children. Palo Alto: Consulting Psychologists Press: Palo Alto; 1973. https://doi.org/10.1037/t06497-000

24. Ozusta HS. Çocuklar için durumluk sürekli kaygı envanteri uyarlama, geçerlik ve güvenirlik çalışması [State trait anxiety inventory adaptation, validity and reliability study for children]. Turk Psikol Derg [Turk J Psychol]. 1995;10:32.
25. Emery RE. Interparental conflict and the children of discord and divorce. Psychol Bull. 1982;92(2):310-30. https://doi.org/10.1037/0033-2909.92.2.310 PMid:7146231

26. Gassman-Pines A, Ananat EO, Fitz-Henley J. COVID-19 and parent-child psychological well-being. Pediatrics. 2020;146(4):e2020007294. https://doi.org/10.1542/peds. 2020-007294 PMid:32764151 PMCid:PMC7546085

27. Luetke M, Hensel D, Herbenick D, Rosenberg M. Romantic relationship conflict due to the COVID-19 pandemic and changes in intimate and sexual behaviours in a nationally representative sample of American adults. J Sex Marital Ther. 2020;46(8):747-62. https://doi.org/10.1080/0092623X. 2020.1810185 PMid:32878584

28. Unver D, Guloglu B. Examination of depression, anxiety and stress in married individuals in the context of relational resilience during the COVID-19 pandemic. Eurasian J Soc Econ Stud. 2021;8(2):517-31.

29. Holman TB, Busby DM. Family-of-origin, differentiation of self and partner, and adult romantic relationship quality. J Couple Relatsh Ther. 2011;10(1):3-19. https://doi.org/10. 1080/15332691.2010.539171

30. Basaran M, Aksoy AB. Views of parents on family life during the Corona-Virus (COVID-19) epidemic. J Int Soc Res. 2020;13(71):668-78.

31. Yildirim M, Gecer E, Akgul O. The impacts of vulnerability, perceived risk, and fear on preventive behaviours against COVID-19. Psychol Health Med. 2021;26(1):35-43. https://doi.org/10.1080/13548506.2020.1776891 PMid: 32490689 